\title{
Information Shocks and the Takeup of Social Programs
}

\author{
David Figlio, Northwestern University and NBER \\ Sarah Hamersma, University of Florida \\ Jeffrey Roth, University of Florida
}

August 2012

\begin{abstract}
We are grateful to the National Science Foundation, National Institutes of Child Health and Human Development, and the RIDGE Center funded by the U.S. Department of Agriculture Economic Research Service for research support, and to the Florida Department of Health for providing us with birth records and program participation data. We appreciate the helpful suggestions of colleagues and seminar participants at Duke University, Institut Sciences Po, National Bureau of Economic Research, Northwestern University, and Norwegian School of Economics. All errors are our own and opinions expressed in this paper do not necessarily reflect those of our employers, funders, or the Florida Department of Health.
\end{abstract}

\section{Introduction}


There exists a long literature attempting to understand what drives participation in social programs. From programs with historically high takeup such as the Earned Income Tax Credit (over 80 percent; see Scholz, 1994) to those with lower takeup such as Medicaid (50-70 percent among eligible children; see Currie and Gruber, 1996) there is continuing discussion over how needy individuals can more effectively be connected with benefits. Research has established that the size of benefits and the ease of claiming them are strong predictors of participation, while factors like stigma or fear of consequences (such as being subject to sanctions or obligations) seem to be less important than was previously feared (Remler and Glied, 2003).

One major reason for non-participation that has been explored is a lack of information about eligibility or program benefits. This issue receives particular attention because there are (at least in theory) policy interventions that could directly address misinformation, particularly via formal communication channels. Daponte et al (1999) used an experimental framework in which they provided customized information about Food Stamp eligibility and benefit levels to a randomly-assigned group of low-income families, and found that participation in Food Stamps increased substantially among this group relative to a control group. Recent work on the EITC by Chetty and Saez (2009) indicates that providing formal information about benefit structure (through tax preparers) can also affect responses to a program’s labor supply incentives. Government-sponsored outreach efforts can also increase participation levels in public programs, although the nature of the spending matters. A study of California's Medi-Cal program outreach concluded that money spent on training application assisters and developing enrollment support via community-based organizations or schools proved effective in increasing participation, while larger media campaigns were ineffective or even counterproductive (Kincheloe and Brown, 2007). Properly targeting the desired audiences with formal information dissemination continues to be elusive.

The more organic spread of information via informal networks - either as a supplement to or an alternative to formal information provision - has also been established as an important predictor of program participation. Huby and Whyley (1996), in a study on a UK social program, find that those who have heard about the program from friends or family are 7.4 times more likely to apply. Dahl, Loken, and Mogstad (2011) demonstrate that peer networks were important transmission mechanisms of information about a new paternity leave policy in 
Norway. In work examining people of varying ethnic backgrounds, Bertrand, Luttmer and Mullainathan (2000) find that eligible individuals who live amongst others who speak their same language are more likely to participate in welfare programs. However, Aizer and Currie (2004) suggest that measured "information" effects of such social networks are difficult to distinguish from other features of a neighborhood, such as factors that are common to people of the same ethnicities or socio-economic opportunities, or uniquely local methods of program implementation. They challenge the information-sharing hypothesis by showing that participation in a publicly-funded prenatal care program in California does not follow the patterns one would expect if information-sharing is a driving force. They find that measured network effects are not larger for people who are likely independently less informed -- women in their first pregnancies as compared to later pregnancies, and immigrant women as compared to native-born women. Their results suggest a potentially limited role for informal informationsharing in program participation decisions, at least when policy conditions are in steady state.

It may be that the information role of social networks is not particularly important when conditions are stable and information is widespread, but these networks may matter more when there is new information to be disseminated. This may be particularly important when there are confusing changes in policy that may not be consistently expressed through formal networks during a transition period (for example, outreach literature may be outdated or caseworkers may still be mastering new rules). However, this is difficult to study because in such a time of policy change, it may be difficult to disentangle the participation effects of information gaps from the effects of the actual policy changes themselves. The very information shocks that can help us understand the role of information (by offering variation in it) are typically attached to real policy changes that may generate substantive changes in behavior.

A unique combination of events provides us with an opportunity to explore program participation during an information shock that does not correspond to an actual policy change in that program. In the mid-to-late 1990s, the U.S. passed major welfare reform legislation that changed some assistance programs but not others. Programs like cash welfare and Medicaid experienced major eligibility changes, including a delinking of cash welfare eligibility and Medicaid eligibility that moved away from a one-stop approach to obtaining public assistance. There is evidence in the literature on these programs that there was substantial confusion and 
concern that influenced participation in an array of assistance programs. For example, Stuber et al. (2000) found via individual surveys that confusion about welfare reform as it applied to Medicaid eligibility was rampant and reduced participation in Medicaid.

One program that was left unchanged was the Special Supplemental Nutrition Program for Women, Infants, and Children (WIC), a widely-used nutritional assistance program available to pregnant and post-partum women and their newborns and young children. Since our goal is to examine the program participation effects of an information shock as distinct from an eligibility change, the unchanged WIC program provides an ideal setting for our analysis. Past work has established that a variety of demographic and (to a lesser extent) program characteristics are predictive of participation (Bitler, Currie, and Scholz, 2003). State-specific costs of participation and benefits from participation have been shown to matter in important ways. Documentation requirements have a deterrent effect on participation (Swann, 2005; Tiehen and Jacknowitz, 2006), while higher-value food packages or adjunctive eligibility for WIC through other program participation can raise WIC participation (Bitler, Currie, and Scholz, 2003). The confusing policy environment of welfare reform represents a new (temporary) cost to getting accurate information about the WIC program, thus potentially deterring participation. In this paper we use rich microdata from Florida to gauge the degree to which informal information channels might help to buffer the information shock of welfare reform, ameliorating the reduction in program participation that typically accompanies such shocks. We attempt to identify a role of social networks that is not likely to be due to local implementation of public programs by accessing a database of detailed natality and program participation records for all Florida births in a 6-year period surrounding welfare reform. We specifically want to see whether people who live near other similar people are more likely to be buffered against the information shock and thus less likely to experience a dip in WIC participation.

While it is generally difficult to define "similar people,” we are able to use information on national origin and geographic location that allows us to move beyond definitions based on general race or ethnicity (as in Aizer and Currie, 2004) or language (as in Bertrand et al, 2000). Because we have the full population of births in Florida over several years, we are able to use a convenient subsample of the population in which identification of social networks is fairly natural: We concentrate our attention exclusively on a set of Spanish speakers not born in the 
United States (whom we'll call Hispanic immigrants for the purposes of clarity) who were eligible to receive WIC during pregnancy, as evidenced by the fact that their birth was funded by Medicaid. ${ }^{1}$ We compare changes in WIC participation amongst Hispanic immigrants living in neighborhoods with a larger concentration of immigrants from their country of origin to those with a smaller concentration of immigrants from their country of origin, holding constant the size of the immigrant population and the share of immigrants in the neighborhood who are Hispanic.

Florida is an outstanding place to study these effects, because there are very large populations of young women who were born in Cuba, Mexico and Puerto Rico, and individuals from these countries live in a variety of neighborhood types from immigrant-scarce to immigrant-dense. ${ }^{2}$ By controlling directly for the interaction between time and the size of the Hispanic population in the neighborhood, we can avoid confounding the effect of own-origin concentration with the role of language or of treatments of Hispanic immigrants in local policy implementation surrounding welfare reform. While it is still possible that local policy implementation could differ in ways that would affect, say, Mexican women in predominantly Cuban neighborhoods differently than they affect Mexican women in predominantly Mexican neighborhoods, it seems more plausible to believe that country-of-origin information flows are at work. As such, our identification strategy provides us with the opportunity to separate the effects of the density of an individual's social network from the effects of the ethnicity of that network.

We find strong evidence to support the notion that social networks mediated the information shock faced by immigrant women in the wake of welfare reform. We observe that Hispanic immigrants, who as a group had reached the same level of WIC participation as nativeborn women during the period immediately prior to welfare reform, experienced the same dip in WIC participation as did native-born mothers during the welfare reform period. But Hispanic immigrants residing in neighborhoods with high own-origin populations did not experience this dip in participation during the welfare reform period. Indeed, similar to Dahl, Loken, and

\footnotetext{
${ }^{1}$ A family income cap of $185 \%$ of the federal poverty level applied both for WIC during pregnancy and Medicaid during pregnancy. See Florida Department of Children and Families (2009).

${ }^{2}$ There are large numbers of young Hispanic women born in other countries as well, but these other Spanish speaking countries, primarily in South and Central America, are combined in the birth vital records.
} 
Mogstad's (2011) findings of a "snowball effect" associated with social networks, we find that women living in own-origin-dense neighborhoods continued to have higher participation in WIC several years after the initial information shock. Our results hold up to a variety of alternative specifications as well as very highly-parameterized models in which we simultaneously compare two groups of women living in the same neighborhood, or giving birth in the same hospital. We find this to be true even when we account for formal information dissemination by controlling for proximity to the nearest WIC office, and we validate the information explanation more fully by showing larger social network effects for first-time mothers. These results indicate that any negative WIC participation effects of uncertainty surrounding welfare reform were much smaller when social networks were likely stronger.

\section{The changing policy climate of the mid-1990s}

The mid-1990s were a time of major change in the social safety net. Major changes in cash welfare programs began with waivers approved by the U.S. Department of Health and Human Services that allowed states to change the rules of welfare program implementation and culminated in the Personal Responsibility and Work Opportunity Reconciliation Act (PRWORA), signed into law in August 1996. ${ }^{3}$ The major elements of the reform were the introduction of a time limit to federal funds spent on each recipient, a transition from matching federal funds to state-specific block grants, and a commensurate surrendering of authority to states for designing and implementing their own programs (which could include work requirements and various forms of sanctions). These changes effectively eliminated the

\footnotetext{
${ }^{3}$ Florida, where we conduct this analysis, began its experimentation with welfare reform in February 1994, when it introduced the Family Transition Program (FTP) in two counties -- Alachua (Gainesville) and Escambia (Pensacola) -- as a very small-scale randomized demonstration experiment. The FTP demonstration was expanded to eight counties in September 1995, including larger counties such as Duval (Jacksonville), Orange (Orlando) and Pinellas (St. Petersburg). A search of Google news archives from late 1995 indicates that this expansion was receiving considerable attention in newspapers in areas not immediately affected, such as Miami, Fort Lauderdale, and Sarasota. The state was actively gearing up to enact statewide welfare reform during this period, as evidenced by the fact that the FTP program was officially implemented statewide only two months after the passage of PRWORA. Note that there was almost no statewide media attention in 1994 surrounding the introduction of the small-scale demonstration project, so there is strong reason to believe that the "welfare reform" era in Florida began in late 1995, affecting women who were giving birth as early as, say, December 1995 or January 1996. Because of the timing of the policy changes and news attention, we treat calendar years as a natural measure of describing overtime changes, though we also report results at the quarterly level.
} 
entitlement nature of cash assistance. New restrictions in eligibility showed immediate effects via reduced participation: National welfare caseloads fell by 30 percent for the nation as a whole between January 1996 and March 1998, with Florida caseloads falling by 49 percent (Urban Institute, 1999).

PRWORA also delinked cash assistance from Medicaid, with additional changes in Medicaid eligibility for some immigrants. ${ }^{4}$ Medicaid became a stand-alone program with potentially distinct eligibility guidelines, and thus individuals previously participating in both programs could become ineligible for one but not the other in light of eligibility changes. In addition, PRWORA eliminated the Medicaid funding of immigrants during the first 5 years of their residency in the United States. While some states covered these immigrants using state funds, Florida did not. However, pregnant immigrants in Florida continued to be presumptively eligible for Medicaid for 45 days of the prenatal period, somewhat reducing the consequences of the eligibility restrictions for pregnant immigrants (our population of interest given our focus on prenatal WIC participation). Undocumented immigrants were not eligible for Medicaid before or after PRWORA, so there was no policy change in that case; undocumented immigrants continue to be eligible only for emergency department services (Minkoff, 2002). Undocumented immigrants' eligibility for Medicaid as a payer for births remained unchanged, as did eligibility (whether for American citizens or undocumented immigrants) for the WIC program.

One might reasonably expect both citizens and immigrants to experience confusion in light of these policy changes. Stuber et al. (2000) provides clear survey evidence of confusion about welfare reform as it applied to Medicaid. In a sample of families with one or more Medicaid recipients or potentially eligible individuals, Stuber et al. (2000) found that 37 percent of surveyed individuals believed (erroneously) that cash welfare work requirements applied to individuals on Medicaid (and 19 percent were unsure). In addition, 28 percent erroneously believed that Medicaid had the same new time limits as cash assistance (and 30 percent were unsure). Since some changes were specific to immigrants, one might expect even more extensive confusion among that population; Stuber et al. (2000) found that 62 percent of respondents answered positively to the statement, "Immigrants are afraid to apply [for

\footnotetext{
${ }^{4}$ There were also limits placed on food stamp participation of immigrants, which provide part of the explanation for falling food stamp caseloads during the welfare reform period (Currie and Grogger, 2001).
} 
Medicaid].” Mazzolari (2004) and Kandula et al. (2004) document reductions in immigrant program participation associated with the chilling effects of the policy climate, and Watson (2010) shows the importance of regional differences in immigration law enforcement in explaining differences in the chilling effects of welfare reform. ${ }^{5}$ Since medical and social service professionals are potentially important sources of information about WIC (and not just Medicaid and cash welfare), one might expect confusion about Medicaid or cash assistance eligibility to potentially affect WIC participation as well, especially among immigrants. Indeed, we find a dip in WIC participation that is coincident with welfare reform despite the consistent eligibility standards of the WIC program over this period.

\section{Hispanic immigrant births and program participation in Florida}

We use a large-scale administrative dataset from Florida to examine WIC participation patterns near the time of welfare reform. Our identification strategy distinguishes the effects of social networks from factors such as local implementation of policies that vary temporally, program implementation that affects speakers of one language differently from speakers of another, or language barriers that may have nothing to do with social networks. The rich data allow us to focus our study on a very tightly-defined population -- Hispanic immigrants who were born in Cuba, Mexico or Puerto Rico, the three Spanish-speaking places outside of the United States that are identified on the birth certificate. ${ }^{6}$ We begin by describing the patterns of births to these Hispanic immigrants in Florida in the years surrounding welfare reform. We make use of data on all live births in Florida between 1994 and 1999 provided to us by the Florida Department of Health, matched with indicators of WIC and Medicaid participation

\footnotetext{
${ }^{5}$ Welfare reform also had effects on program participation in other dimensions, such as health care utilization. See, e.g., Bitler, Gelbach and Hoynes (2005).

${ }^{6}$ The birth certificate does have a space to enter in another place of birth for the mother, but the evidence suggests that either few people enter data in this space or that it rarely is entered into the official records. Fully 97.6 percent of those marking "other country" on the birth certificate have "other country" recorded in the space where a country would be named. As a consequence, while the birth records and the American Community Survey are within onetenth of a percentage point of the rate of births to mothers born in Cuba, Mexico, and Puerto Rico, the American Community Survey reports an order of magnitude more mothers born in countries such as Colombia and the Dominican Republic. In addition, while the birth certificate lists "Filipino" as an ethnicity choice, only a small fraction of Filipino women in the United States report Spanish as their first language. We therefore are only comfortable using data for mothers born in Cuba, Mexico, and Puerto Rico.
} 
during pregnancy. During this time period the number of births in Florida was increasing, with about 16,000 births per month in 1994 and about 16,500 births per month in 1999. Figure 1 zeroes in on the share of immigrants as a percentage of total births in Florida: The number of births to immigrant women increased by an even larger degree during this period, from 22 percent of all births in 1994 to 26 percent of all births in 1999, and the percentage of births to Hispanic immigrant women increased from under 13 percent in 1994 to over 15 percent in 1999. The percentage of all births to mothers born in Cuba, Mexico and Puerto Rico -- the places of birth of the mothers in our study population -- increased from 6 percent in 1994 to 8 percent in 1999. And as can be seen in Figure 1, these percentages have been approximately monotonically increasing over the entire study period; there is no evidence that immigrant births changed in any sudden ways over the time series. Because we further restrict our study to women who were eligible for WIC during pregnancy -- as evidenced by the fact that the birth was paid for by Medicaid -- our study population is the set of 45,528 births to women from Cuba, Mexico or Puerto Rico who were eligible for WIC during pregnancy and resided in a zip code with at least ten births (regardless of immigrant status) in each of the six calendar years of the study. ${ }^{7}$

While the fraction of births to Hispanic immigrants (either those from the countries considered in this study or overall) changed only gradually over our study period, the relative WIC participation rates of Hispanic immigrants versus native-born eligible women changed quite dramatically. As can be seen in Figure 2, at the beginning of the study period Hispanic immigrants' WIC participation rate was more than ten percentage points lower than the overall participation rate, but by the end of the period Hispanic immigrants' participation rates actually exceeded the native-born participation rate. The reversal can be linked to two time periods: First, in late 1995 Hispanic immigrants' WIC participation rates increased sharply to catch those of native-born participation rates. Second, while both Hispanic immigrants' and native born eligible

\footnotetext{
${ }^{7}$ We make this last restriction because we calculate the immigrant percentages based on the observed attributes of mothers living in zip codes, and wish to ensure that we have a reasonably-sized denominator for these calculations. In practice, this sample restriction has tiny effects on our overall sample size; only 3.4 percent of all mothers in Florida (and 2.8 percent of Hispanic immigrant mothers) lived in zip codes that do not meet this restriction, and the median mother lived in a zip code with 307 or more births in each year of the study (393 for Hispanic immigrants.) The tenth percentile mother lived in a zip code with 64 or more births in each year (100 for Hispanic immigrants.)
} 
mothers' participation rates dipped during the welfare reform period of 1996 and 1997, the participation rates of Hispanic immigrants remained in steady state moderately higher than that of native-born mothers. These patterns lead us to consider whether the neighborhoods and social networks that Hispanic immigrants occupy could play a role in explaining these findings.

\section{Social networks as information channels}

Our objective is to identify whether social networks played a role in the degree to which prenatal WIC participation rates changed in the "information shock" period surrounding welfare reform. While it is impossible to measure social networks directly in the administrative datasets available to us, we believe that immigrant women are more likely to be acquainted with and share information with other women of their same nationality than they are with other immigrant women from different nationalities. We therefore hypothesize that immigrant women who live near other immigrant women from the same country will have better information about program rules than might immigrant women who live in communities with fewer immigrants from the same country. But as Aizer and Currie (2004) point out, correlations between concentration of an ethnicity in a neighborhood and members of that ethnicity's propensity to participate in a program could reflect many factors, including local program implementation. Our strategy is to distinguish between immigrant neighbors from one's own country and immigrant neighbors who simply share the same language; thus we can more distinctly identify the potential for information networks amongst immigrant women.

In order to compare immigrant women in communities with few neighbors from the same country to those in communities with many neighbors from their country of origin, we must have immigrant women living in a variety of communities that differ both by (1) the concentration of Hispanic immigrants in the neighborhood and (2) the concentration of Hispanic immigrants of their same national origin. As can be seen in Figure 3, Hispanic immigrant women live in a wide variety of neighborhoods, as defined by the share of all births to Hispanic immigrants. While some live in neighborhoods with almost no other Hispanic immigrant mothers, others live in neighborhoods where more than four-fifths of all mothers are Hispanic immigrants. More to the point of the paper, Figure 4 presents information about the degree to which Hispanic immigrants live in neighborhoods that vary considerably in the concentration of immigrants from their own 
countries. There are some women who live in neighborhoods with very few immigrants from their same place of origin, while other women live in neighborhoods in which one-third, onehalf, or more of the women giving birth are also immigrants from the same place of origin. It is clear that there exists substantial variation in the composition of the neighborhoods in which Hispanic immigrants reside; the question is whether these differences in composition can explain differences in WIC participation rates during a period in which information is disrupted.

To fix ideas, we begin by presenting a time-series figure that compares native-born participation rates to Hispanic immigrant participation rates, separated by the percentage ownorigin in the neighborhood. As seen in Figure 5, Hispanic immigrants' participation rates began the study period below native-born participation rates regardless of the degree of own-origin concentration. The time series plots in high and medium percent own-origin communities track one another very closely in the pre-welfare reform period. Following welfare reform, however, the time series of low and medium percent own-origin track the native-born participation rates very closely, with the high own-origin concentration neighborhoods steadily ahead over the rest in terms of participation. Figure 6 zeroes in on our identifying variation, as it presents the breakdown by residual percent own-origin after controlling for percent immigrant and percent Hispanic immigrant. The time series patterns are even clearer in this figure. The remainder of the paper involves placing confidence bands around variations on this basic theme.

\section{Estimates of the effects of social networks on participation during information shocks}

Our estimating equation of interest is

$$
\mathrm{W}_{\mathrm{izt}}=\alpha_{\mathrm{t}}+\theta_{\mathrm{z}}+\beta \mathrm{M}_{\mathrm{iz}} \cdot \mathrm{t}_{\mathrm{t}}+\gamma \mathrm{H}_{\mathrm{iz}} \cdot \mathrm{t}_{\mathrm{t}}+\delta \mathrm{O}_{\mathrm{iz}} \cdot \mathrm{t}_{\mathrm{t}}+\sigma \mathrm{X}_{\mathrm{izt}}+\varepsilon_{\mathrm{izt}},
$$

where W represents the WIC participation during pregnancy of mother i living in neighborhood z during time $\mathrm{t}, \mathrm{M}$ represents the percentage of births to immigrant women in the mother's neighborhood, $\mathrm{H}$ represents the percentage of births to Hispanic immigrants in the mother's neighborhood, O represents the percentage of births to immigrants from the mother's home country in the mother's neighborhood, and X represents a set of mother-specific covariates 
(maternal age, education level and country of origin.) The coefficients $\alpha, \beta, \gamma$ and $\delta$ are all vectors, with different coefficients estimated for each quarter ${ }^{8}$ between January 1994 and December 1999. We control for neighborhood fixed effects $\theta$ to reflect the fact that there may be systematic differences in program takeup at the neighborhood level that are time-invariant. Our coefficients of interest are the $\delta$ s, the estimated relationships between the fraction of own-origin women in the neighborhood and a mother's WIC participation during pregnancy, holding constant the immigrant concentration and Hispanic immigrant concentration in the neighborhood, at different points in time. We cluster all the standard errors at the neighborhood level, and we measure the neighborhood as the zip code of residence at the time of the birth. Again, we limit our analysis to pregnancies in which the births were funded by Medicaid, so that we know that all women in the study, even undocumented immigrants, were eligible to participate in WIC during their pregnancies.

While our primary specifications rely on the notion that neighborhoods with different attributes may respond differently during the information shock period around welfare reform, it is important to note that neighborhoods are likely settled by different types of individuals who might react differently to the information shock. There is little evidence that high school dropouts and high school graduates live in different types of neighborhoods in terms of immigrant densities -- the typical neighborhood occupied by a high school dropout in our population is 17.8 percent own-origin immigrant, as compared with 17.0 percent own-origin immigrant in the typical neighborhood occupied by a high school graduate $(p=0.647)$. However, there is a strong age gradient in the likelihood of living near other immigrants from one's own country of origin: While neighborhoods occupied by immigrants 20 and under averaged 15.4 percent own-origin immigrant, this figure rises monotonically with age, from 16.8 percent for those aged 21-25 to 18.3 percent for those aged 26-30 to 19.5 percent for those aged 31 and older $(p=0.000)$. Note that this is likely due to differential location patterns at the time of immigration rather than any general patterns leading immigrants to move to relatively homogeneous

\footnotetext{
${ }^{8}$ Here and throughout the paper, when we refer to a quarter, we are referring to the quarter-year combination, so that all of our models interacting quarter with various variables have 24 interactions to reflect the 6 years. We have also estimated the same models using monthly interactions, and the pattern of results is fundamentally the same. In practice, for ease of interpretation we aggregate the quarterly interaction coefficients to the annual level in most of our analyses presented herein.
} 
neighborhoods as they age: When we compare the neighborhood attributes of the 4,679 mothers in our study who moved zip codes between births, we find that 33.6 percent moved to neighborhoods with percent own origin more than 3 percentage points above their previous neighborhood, 33.4 percent moved to neighborhoods with percent own origin more than 3 percentage points below their previous neighborhood, and 33.0 percent moved to neighborhoods with percent own origin within 3 percentage points of their previous neighborhood. Nonetheless, as a further check to ensure that we are not ascribing social network effects to other changes occurring in specific neighborhoods housing particular types of immigrants, in some specifications, we go further still and estimate models with time-specific neighborhood-specific fixed effects:

$$
\mathrm{W}_{\mathrm{izt}}=\alpha_{\mathrm{zt}}+\beta \mathrm{M}_{\mathrm{iz}} \cdot \mathrm{t}_{\mathrm{t}}+\gamma \mathrm{H}_{\mathrm{iz}} \cdot \mathrm{t}_{\mathrm{t}}+\delta \mathrm{O}_{\mathrm{iz}} \cdot \mathrm{t}_{\mathrm{t}}+\sigma \mathrm{X}_{\mathrm{izt}}+\varepsilon_{\mathrm{izt}} \cdot
$$

In these highly parameterized specifications, we explicitly compare Cubans to Puerto Ricans to Mexicans within the same neighborhood at the same time. In addition, because there exists the possibility that women using the same types of medical services might receive different types of information (as suggested by Aizer and Currie, 2004), we also estimate variants of equation (2) with birth hospital-by-time fixed effects rather than neighborhood-by-time fixed effects. We report the results of these various specifications below.

The first row of Table 1 reports the results of the estimates of equation (1), in which all coefficient estimates are aggregated to the annual level and compared with 1994 for ease of interpretation. (The quarterly version of this same table is presented graphically in Figure 7.) As can be seen in the table, there is no apparent differential effect of being in a high own-origin neighborhood in 1995 versus 1994, in the period before welfare reform began in earnest in Florida. But in 1996 a gap that is large in magnitude and statistical significance opened up: For every ten-percentage-point increase in the percentage own-origin in a neighborhood, holding constant time-specific effects of percent immigrant and percent Hispanic immigrant and timeinvariant neighborhood fixed effects, a woman's WIC participation rate increased by three percentage points. And even in the longer-run, this differential effect appears to have stabilized at about a two percentage point jump. These results present evidence that having more women 
from the same place of origin increased a woman's likelihood of participating prenatally in the WIC program during a time of general confusion about eligibility.

While we would have ideally been able to compare across a wider range of nationalities, we are limited by the construction of the administrative data to only compare Cubans, Mexicans, and Puerto Ricans. While these groups are all equally eligible for WIC, they vary considerably in their eligibility for other programs, and they received very different treatments during welfare reform. Puerto Ricans are American citizens, while the minority of Cubans and Mexicans are American citizens. ${ }^{9}$ It is therefore useful to know whether our results are driven by Puerto Ricans, whose security as American citizens is not in question. ${ }^{10}$ Therefore, in the second row of Table 1 we repeat the analysis looking only at Cubans and Mexicans. The point estimates are slightly larger when we exclude Puerto Ricans, implying that the results are more driven by the groups where the minority are American citizens rather than the group where all members are American citizens.

We are agnostic about exactly when the welfare reform era began in Florida because we have no way of knowing exactly how much information had spread throughout the state, and when exactly the information spread. That said, it is possible to look separately at the eight counties in which welfare reform was implemented first via Florida's September 1995 Family Transition Program waiver and the 59 counties still nominally under the pre-welfare reform regime until the middle of 1996. The third and fourth rows of Table 1 differentiate the births into counties with early implementation and counties with later implementation; because the sample size of women in the early implementation counties is so small (15.9 percent of the study population, and largely concentrated in a handful of zip codes), the point estimates are too imprecise to draw conclusions. However, the raw magnitudes of the estimates at least are quite large in the early implementation counties. While the larger estimated results are consistent with

\footnotetext{
${ }^{9}$ According to the 2000 Census of Population, 17 percent of Mexican-born new mothers and 46 percent of Cubanborn new mothers in Florida were American citizens. The birth records do not report the citizen status or documentation status of mothers giving birth.

${ }^{10}$ Even if the results were driven by Puerto Ricans, this would not invalidate our study, as this is a study about information rather than immigration per se, but a set of results driven by Puerto Ricans may raise other questions about interpretation.
} 
an information shock and social network story, we are too uncertain to want to make that claim, and report the disaggregated results purely for the sake of completeness.

We hypothesize that immigrant women might be especially reliant on information channels when the pregnancy is their first, so we next restrict the analysis to first pregnancies. This is a particularly important check of the information channels story, since Aizer and Currie (2004) suggest the first birth comparison can be an important way to identify the women likely to be most sensitive to information about social programs. As can be seen from the fifth and sixth rows of Table 1, the estimated effects of having a larger fraction of women in the neighborhood who were themselves immigrants from the same country are substantially larger when restricting the study population to first births. This is particularly important in the medium-to-long-run, suggesting a snowball effect phenomenon - in which one person who is induced to participate then helps induce others - similar to that found by Dahl, Loken, and Mogstad (2011) in their study of the takeup of Norwegian paternal leave benefits.

\section{Robustness checks}

Because people with different likelihoods of participating in the program at different times might have settled in different neighborhoods, as an extra check we repeat the same analysis but include zip-code-by-time fixed effects (equation (2) above.) In this specification, we are now directly comparing different own-origin groups in the same neighborhood at the same time, and identifying solely off of the relative sizes of the different Hispanic national groups in the neighborhood. The results, reported in the second row of Table 2, are less statistically significant than those in the previous specifications, but the pattern of findings -- that the larger the own-origin group in the neighborhood, the more likely a Hispanic immigrant was to participate in WIC during pregnancy during the information shock period -- persists. Likewise, in the third row of Table 2 we estimate a variant of equation (2) in which we control for hospital-by-time fixed effects to take into account the possibility that different medical facilities cater to different populations of mothers; the results still suggest that Hispanic immigrants are more likely to participate in WIC when they have more own-origin immigrant mothers in their neighborhood. 
We next consider whether the results are robust to a different measure of geographic concentration of immigrants, calculated not from the birth records themselves but from the 2000 Census of Population. We use Census figures to calculate the share of women with young children in each Public-Use Microdata Area (PUMA) in Florida who are immigrants, Hispanic immigrants, or of Puerto Rican, Mexican, or Cuban origin. Though these counts are based on considerably larger geographical units (there are about seven zip codes for each PUMA on average) and so they therefore are less precise measures of a community, and though PUMAs are considerably more ethnically heterogeneous than are zip codes in general, they should provide at least some information about neighborhood composition. The results are reported in the fourth row of Table 2. While the results are slightly smaller (with the increase in participation rates associated with percentage own-origin in the community being gradual between 1995 and 1997 rather than more immediate in 1996) the pattern of results remains consistent even with this weaker definition of neighborhood coming from a different data source.

We also test the sensitivity of our results to transformations in the percent own-origin variable, and measure the percent own-origin (as well as percent Hispanic immigrant and percent immigrant) as, in turn, the log of the percent own-origin and the log of the number of total ownorigin births in the zip code. These results are reported in the fifth and sixth rows of Table 2. While the level of statistical significance is weaker in these model specifications, they continue to support the general pattern of findings that the larger the concentration of women from one's own country of origin, the more likely that a woman will have participated in the WIC program during the period in which information about program eligibility was disrupted.

In addition, we conduct a series of falsification tests to help to ensure that the results that we generate are not merely a statistical artifact or, alternatively, driven by compositional changes in the population of Hispanic immigrants giving birth. Table 3 presents the results of falsification tests in which we replace WIC participation as a dependent variable with three alternate dependent variables -- maternal age, a dummy for whether the mother is a high school dropout, and a dummy for whether this is not the first birth. As can be seen in Table 3, there is no pattern in the results in these falsification tests. Therefore, we are more confident that the results reported herein are due to genuine responses in WIC participation of women facing different local conditions. 


\section{Program office proximity as a substitute for local network}

Our results are consistent with a story that local networks of own-origin individuals play a role in mitigating information shocks. This finding begs the question of whether government agencies might be able to place offices strategically to help to mitigate information shocks as well. In order to gauge the degree to which program office proximity might serve as a substitute for social networks, we repeat the above analyses, but augment the model with a series of WIC office-proximity-by-time variables. Specifically, we include a variable regarding WIC office proximity, where we observe whether a WIC program office was within two miles of the centroid of the zip code (42.3 percent of the population.) This measure of WIC office proximity is not perfect; most importantly, the earliest information we have about specific locations of WIC offices in Florida is in 1998, so we may be measuring WIC office locations during the information shock period with error. That said, we have reason to believe that this measurement error is not very large: For instance, in 1998, zip codes with WIC offices within two miles had a 2.8 percent higher takeup rate than those where the nearest WIC office was over two miles away, and in 1994, the first year of our data, the difference was a statistically indistinguishable 1.7 percent. If there was a major change in WIC office locations during our study period, it is not being reflected in substantial changes in WIC takeup patterns.

Table 4 presents our head-to-head comparisons of the estimated effects of percent ownorigin in the neighborhood at different time periods to the estimated effects of having a proximate WIC office during the same time period. As can be seen in the table, we do not observe statistically significant estimated effects of WIC office proximity during the critical time period, and to the extent to which the WIC office proximity interactions are substantial in magnitude, they have a negative sign, indicating that if anything, having a WIC office nearby might have reduced, rather than enhanced, WIC takeup amongst our population during the information shock time period. On the other hand, our estimated social network effects remain robust to the inclusion of the WIC office time interactions. While these results are not conclusive, they provide additional evidence that program office proximity is not a substitute for social networks during information shocks. 
While WIC office proximity appears to not be a substitute for social networks, this proximity might still affect the degree to which social networks influence program participation in a time of information shocks. We therefore estimate models in which interact our percent own-origin measure with a measure for WIC offices within two miles. The interactions are negative though statistically insignificant, while the estimated effects of percent own-origin on WIC participation remains strong and positive. Therefore, there is little evidence to suggest that merely placing more offices nearby in a time of widespread confusion does a better job than indicators of local networks in stimulating WIC participation. We intend to explore this relationship further in future research.

\section{Conclusion}

We present new evidence suggesting that social networks provide information that might help to reduce confusion during information shocks. We employ a unique dataset and empirical methodology that allow us to rule out local program implementation factors, ethnic background itself, or shared language as explanations for why program participation is higher in communities where social networks are likely to be stronger. Since we are controlling for ethnic background, we are able to disentangle the effect of the density of the social network from the ethnicity of the network in our analysis. While we do not provide long-run equilibrium explanations of correlations amongst similar individuals in their economic activity or program participation, this

research does indicate that social networks may play an important role in the short run. That said, the fact that the results appear to persist for several years beyond the time of the initial information shock suggests that there may be ongoing effects, a la Dahl, Loken, and Mogstad (2011), in operation.

The fact that we find that program office proximity itself is not related to changes in WIC program takeup during the information shock period but measures of information networks seem to be influential suggests that government agencies desiring to increase program takeup among eligible potential participants may wish to consider a wide variety of information diffusion methods, rather than relying solely on locating program offices in strategic locations. Our evidence on the potential role of social networks suggests that using social networks to spread 
information about eligibility rules and benefits may be successful in reducing the likelihood of major reductions in program participation in periods of information shocks. 


\section{References}

Aizer, A., Currie, J., 2004. Networks or neighborhoods? Correlations in the use of publiclyfunded maternity care in California. Journal of Public Economics 88, 2573-2585.

Bertrand, M., Luttmer, E., Mullainathan, S., 2000. Network effects and welfare cultures. Quarterly Journal of Economics CXV, 1019-1056 (August).

Bitler, M, Currie, J., Scholz, 2003. WIC Eligibility and Participation. The Journal of Human Resources XXXVIII, 1139-1179

Bitler, M., Gelbach, J., Hoynes, H., 2005. Welfare Reform and Health. Journal of Human Resources XL (2): 309-334.

Borjas, G., 2000. The Economic Progress of Immigrants. NBER Chapters, in: Issues in the Economics of Immigration, NBER, 15-50.

Chetty, R., Saez, E., 2009. Teaching the Tax Code: Earnings Responses to an Experiment with EITC Recipients. NBER Working Paper \#14836, April 2009.

Currie, J., Gruber, J., 1996. Health Insurance Eligibility, Utilization of Medical Care, and Child Health. Quarterly Journal of Economics 111(2), 431- 466 (May). B

Currie, J., Grogger, J., Burtless, G., Schoeni, R., 2001. Explaining Recent Declines in Food Stamp Program Participation. Brookings-Wharton Papers on Urban Affairs, 203-244.

Dahl, G., Loken, K., Mogstad, M. 2011. Peer Effects in Program Participation. Working paper, University of California-San Diego.

Daponte, B., Sanders, S., Taylor, L., 1999. Why Do Low-Income Households not Use Food Stamps? Evidence from an Experiment. The Journal of Human Resources, 34(3), 612-628 (Summer).

Duflo, E., Saez, E., 2003. The Role Of Information And Social Interactions In Retirement Plan Decisions: Evidence From A Randomized Experiment. The Quarterly Journal of Economics 118(3), 815-842 (August).

Edin, P., Fredriksson, P., Åslund, O., 2003. Ethnic Enclaves And The Economic Success Of Immigrants - Evidence From A Natural Experiment. The Quarterly Journal of Economics 118(1), 329-357 (February).

Florida Department of Children and Families, 2009. Family-Related Medicaid Programs Fact Sheet.

Huby, M., Whyley, C., 1996. Take-up and the Social Fund. Journal of Social Policy, 25, 1-18. 
Jackson, C. K., Scheider, H., 2010. Do Social Connections Reduce Moral Hazard? Evidence from the New York City Taxi Industry. NBER Working Paper \#16279, August 2010.

Jackson, M., 2010. Social and Economic Networks. Princeton, NJ: Princeton University Press.

Kandula N., Grogan C., Rathouz P., Lauderdale D., 2004. The unintended impact of welfare reform on the medicaid enrollment of eligible immigrants. Health Services Research 39(5):15091526 (October).

Kincheloe, J., Brown, E. R., 2007. The Effect of County "Outreach Environments" on Family Participation in Medi-Cal and Healthy Families. UC Los Angeles: UCLA Center for Health Policy Research.

Mazzolari, F., 2004. Effects of Welfare Reform on Immigrants’ Welfare Participation: How "Chilling” are They? mimeo (September).

Minkoff, H., 2002. Welfare Reform and the Perinatal Health of Immigrants. The Maternal and Child Health Research Program, Maternal and Children Bureau, (December).

Munshi, K., 2003. Networks In The Modern Economy: Mexican Migrants In The U.S. Labor Market. The Quarterly Journal of Economics 118(2), 549-599 (May).

Remler, D., Glied, S., 2003. What Other Programs Can Teach Us: Increasing Participation in Health Insurance Programs. American Journal of Public Health 93(2), 67-74 (January).

Scholz, J.K., 1994. The Earned Income Tax Credit: Participation, Compliance, and Anti-poverty Effectiveness,” National Tax Journal, March, 1994, 59-81.

Stuber, J., Maloy, K., Rosenbaum, S., Jones, K., 2000. Beyond Stigma: What Barriers Actually Affect the Decisions of Low-Income Families to Enroll in Medicaid? Center for Health Services Research and Policy, The George Washington University School of Public Health and Health Services. July 2000.

Swann, C., 2007. The Timing of Prenatal WIC Participation, The B.E. Journal of Economic Analysis \& Policy, Berkeley Electronic Press, vol. 7(1), pages 5.

The Urban Institute, 1999. Income Support and Social Services for Low-Income People in Florida, February 1999.

Tiehen, L., Jacknowitz, A., 2006. Why Wait?: Examining Delayed WIC Participation Among Pregnant Women. Economic Research Service, U.S. Department of Agriculture, March 2006.

Watson, T., 2010. Inside the Refrigerator: Immigration Enforcement and Chilling in Immigrant Medicaid Participation. NBER Working Paper \#16278, August 2010. 
Table 1: Estimated effects of percent own-origin in neighborhood on the probability of WIC participation; estimates aggregated to the annual level, compared with 1994

\begin{tabular}{llllll}
\hline \hline & 1995 & 1996 & 1997 & 1998 & 1999 \\
\hline Baseline results & -0.010 & $0.307^{* * *}$ & $0.162^{*}$ & $0.201^{* *}$ & $0.230^{* *}$ \\
& $(0.074)$ & $(0.094)$ & $(0.099)$ & $(0.101)$ & $(0.096)$ \\
\hline Only Mexicans and Cubans & 0.066 & $0.551^{* * *}$ & $0.299^{* *}$ & $0.298^{* *}$ & $0.328^{* * *}$ \\
& $(0.084)$ & $(0.120)$ & $(0.123)$ & $(0.128)$ & $(0.116)$ \\
\hline Counties with early implementation & -0.936 & 1.456 & 0.586 & 1.022 & 0.406 \\
& $(1.628)$ & $(1.800)$ & $(1.603)$ & $(1.656)$ & $(1.577)$ \\
Counties with later implementation & -0.050 & $0.264^{* * *}$ & $0.193^{*}$ & $0.247 * *$ & $0.242^{* *}$ \\
& $(0.072)$ & $(0.096)$ & $(0.109)$ & $(0.108)$ & $(0.103)$ \\
\hline Women with prior birth experience & -0.085 & $0.270^{* * *}$ & 0.080 & 0.096 & 0.113 \\
& $(0.101)$ & $(0.103)$ & $(0.111)$ & $(0.116)$ & $(0.115)$ \\
First births & 0.106 & $0.383^{* *}$ & $0.299^{* *}$ & $0.352 * * *$ & $0.421^{* * *}$ \\
& $(0.125)$ & $(0.148)$ & $(0.146)$ & $(0.131)$ & $(0.145)$ \\
\hline \hline
\end{tabular}

Notes: Standard errors clustered at the zip code level are reported beneath coefficient estimates. The dependent variable is an indicator for maternal WIC participation during pregnancy. Model specifications include zip code fixed effects, controls for dummy variables for maternal education and maternal place of origin, and quarter-specific zip code-level percent immigrant and percent Hispanic immigrant. The coefficient estimates reported are annual averages of the quarter-specific coefficients on zip code own-origin percentage, compared with 1994. Estimates marked $* * *, * *$, and $*$ are statistically significant at the 1,5 , and 10 percent levels, respectively. Number of observations: 45,528 births in 778 zip codes. 
Table 2: Heterogeneity in the estimated effects of percent own-origin in neighborhood on the probability of WIC participation, by model specification; estimates aggregated to the annual level, compared with 1994

\begin{tabular}{llllll}
\hline \hline & 1995 & 1996 & 1997 & 1998 & 1999 \\
\hline Baseline results & -0.010 & $0.307^{* * *}$ & $0.162^{*}$ & $0.201^{* *}$ & $0.230^{* *}$ \\
& $(0.074)$ & $(0.094)$ & $(0.099)$ & $(0.101)$ & $(0.096)$ \\
\hline Adding zip code x quarter fixed effects & -0.201 & 0.149 & $0.209^{*}$ & $0.222^{*}$ & $0.213^{*}$ \\
& $(0.109)$ & $(0.121)$ & $(0.115)$ & $(0.126)$ & $(0.128)$ \\
\hline Adding hospital x quarter fixed effects & -0.039 & $0.325^{* * *}$ & $0.327^{* * *}$ & $0.399^{* * *}$ & $0.389^{* * *}$ \\
& $(0.080)$ & $(0.094)$ & $(0.094)$ & $(0.088)$ & $(0.102)$ \\
\hline Key variable measured using Census & -0.113 & 0.063 & $0.195^{*}$ & $0.202^{*}$ & $0.285^{* *}$ \\
data instead of birth records data & $(0.093)$ & $(0.100)$ & $(0.102)$ & $(0.121)$ & $(0.117)$ \\
\hline Key variable: log of percent own- & $-0.021^{*}$ & $0.028^{* *}$ & 0.018 & $0.025^{*}$ & $0.023^{*}$ \\
origin & $(0.011)$ & $(0.012)$ & $(0.013)$ & $(0.014)$ & $(0.014)$ \\
\hline Key variable: log of total number of & $-0.023^{* *}$ & $0.022^{*}$ & 0.015 & 0.020 & 0.020 \\
own-origin births & $(0.011)$ & $(0.012)$ & $(0.013)$ & $(0.014)$ & $(0.014)$ \\
\hline \hline
\end{tabular}

Notes: Standard errors clustered at the zip code level are reported beneath coefficient estimates. The dependent variable is an indicator for maternal WIC participation during pregnancy. Model specifications include zip code fixed effects, controls for dummy variables for maternal education and maternal place of origin, and quarter-specific zip code-level percent immigrant and percent Hispanic immigrant. The coefficient estimates reported are annual averages of the quarter-specific coefficients on zip code own-origin percentage, compared with 1994. Estimates marked $* * *, * *$, and $*$ are statistically significant at the 1,5 , and 10 percent levels, respectively. Number of observations: 45,528 births in 778 zip codes. 
Table 3: Falsification tests: Estimated effects of percent own-origin in neighborhood on certain maternal attributes; estimates aggregated to the annual level, compared with 1994

\begin{tabular}{llllll}
\hline \hline & 1995 & 1996 & 1997 & 1998 & 1999 \\
\hline Baseline results & -0.010 & $0.307^{* * *}$ & $0.162^{*}$ & $0.201^{* *}$ & $0.230^{* *}$ \\
& $(0.074)$ & $(0.094)$ & $(0.099)$ & $(0.101)$ & $(0.096)$ \\
\hline Dependent variable: Maternal age & -0.334 & -0.117 & -0.331 & 0.875 & 0.465 \\
& $(0.803)$ & $(0.945)$ & $(0.789)$ & $(1.014)$ & $(1.045)$ \\
\hline Dependent variable: Mom has fewer & $0.173^{* *}$ & 0.057 & -0.013 & 0.072 & 0.082 \\
than 12 years of education & $(0.073)$ & $(0.072)$ & $(0.061)$ & $(0.068)$ & $(0.072)$ \\
\hline Dependent variable: Not the first birth & 0.018 & 0.041 & -0.069 & 0.020 & -0.003 \\
& $(0.071)$ & $(0.076)$ & $(0.071)$ & $(0.082)$ & $(0.077)$ \\
\hline \hline
\end{tabular}

Notes: Standard errors clustered at the zip code level are reported beneath coefficient estimates. The dependent variable in the first row is an indicator for maternal WIC participation during pregnancy. Model specifications include zip code fixed effects, controls for dummy variables for maternal education and maternal place of origin, and quarter-specific zip code-level percent immigrant and percent Hispanic immigrant. The coefficient estimates reported are annual averages of the quarter-specific coefficients on zip code own-origin percentage, compared with 1994. Estimates marked $* * *, * *$, and $*$ are statistically significant at the 1,5 , and 10 percent levels, respectively. Number of observations: 45,528 births in 778 zip codes. 
Table 4: The relative influence of percentage own-origin versus local availability of a WIC office on WIC participation; estimates aggregated to the annual level, compared with 1994

\begin{tabular}{llllll}
\hline \hline & 1995 & 1996 & 1997 & 1998 & 1999 \\
\hline Baseline results & -0.010 & $0.307^{* * *}$ & $0.162^{*}$ & $0.201^{* *}$ & $0.230^{* *}$ \\
& $(0.074)$ & $(0.094)$ & $(0.099)$ & $(0.101)$ & $(0.096)$ \\
\hline Percent own-origin in zip code & -0.037 & $0.265^{* * *}$ & $0.239^{* *}$ & $0.209^{* *}$ & $0.325^{* * *}$ \\
& $(0.084)$ & $(0.097)$ & $(0.100)$ & $(0.102)$ & $(0.126)$ \\
WIC office within 2 miles of zip code & 0.003 & -0.037 & -0.031 & -0.046 & -0.019 \\
centroid & $(0.023)$ & $(0.028)$ & $(0.027)$ & $(0.033)$ & $(0.029)$ \\
\hline Percent own-origin in zip code & 0.024 & $0.355^{* * *}$ & $0.275^{*}$ & 0.228 & $0.441^{* * *}$ \\
& $(0.121)$ & $(0.137)$ & $(0.148)$ & $(0.152)$ & $(0.166)$ \\
WIC office within 2 miles of zip code & 0.018 & -0.015 & -0.021 & -0.040 & 0.009 \\
centroid & $(0.030)$ & $(0.036)$ & $(0.037)$ & $(0.044)$ & $(0.041)$ \\
Percent own-origin x WIC office within & -0.103 & -0.142 & -0.062 & -0.031 & -0.182 \\
2 miles of centroid & $(0.130)$ & $(0.123)$ & $(0.139)$ & $(0.141)$ & $(0.155)$ \\
\hline \hline
\end{tabular}

Notes: Standard errors clustered at the zip code level are reported beneath coefficient estimates. The dependent variable is an indicator for maternal WIC participation during pregnancy. Model specifications include zip code fixed effects, controls for dummy variables for maternal education and maternal place of origin, and quarter-specific zip code-level percent immigrant and percent Hispanic immigrant. The coefficient estimates reported are annual averages of the quarter-specific coefficients on zip code own-origin percentage, compared with 1994. Estimates marked $* * *, * *$, and * are statistically significant at the 1,5 , and 10 percent levels, respectively. Number of observations: 45,528 births in 778 zip codes. 
Figure 1: Immigrants as a percentage of total births in Florida, by month

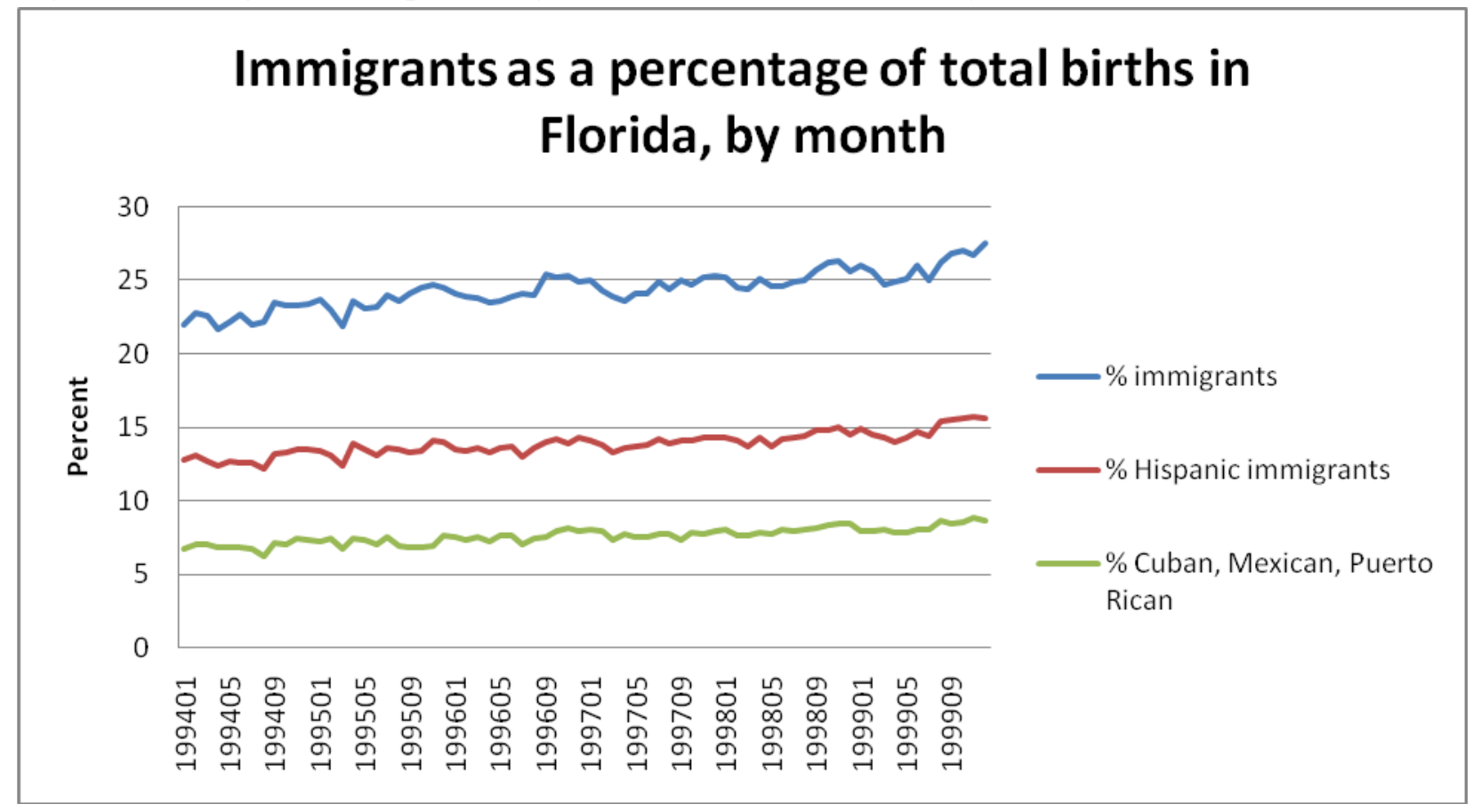


Figure 2: WIC participation rates for eligible Hispanic immigrants and all Medicaid-funded births, by quarter

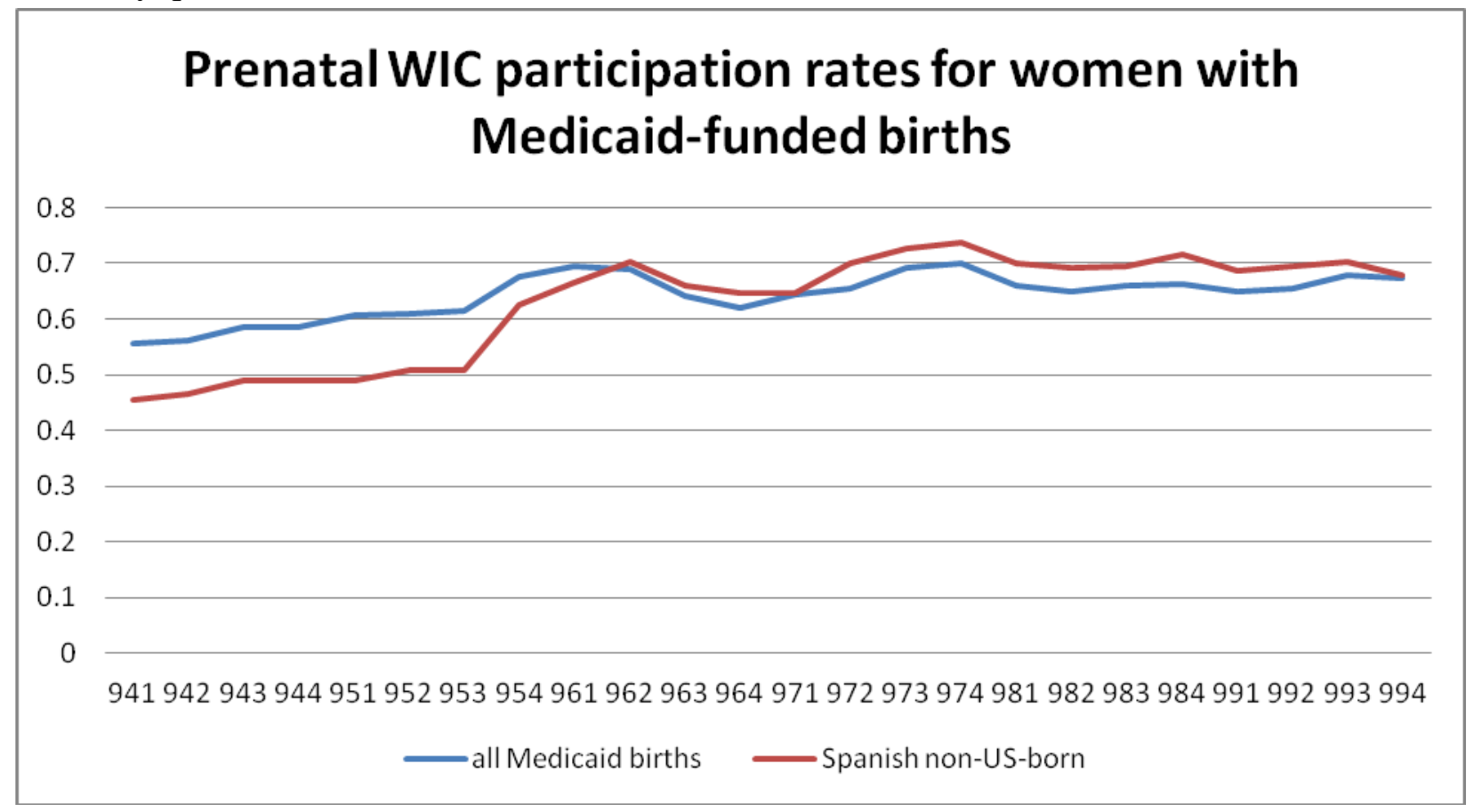


Figure 3: Distribution of percent Hispanic immigrants in zip code of residence, Hispanic immigrants

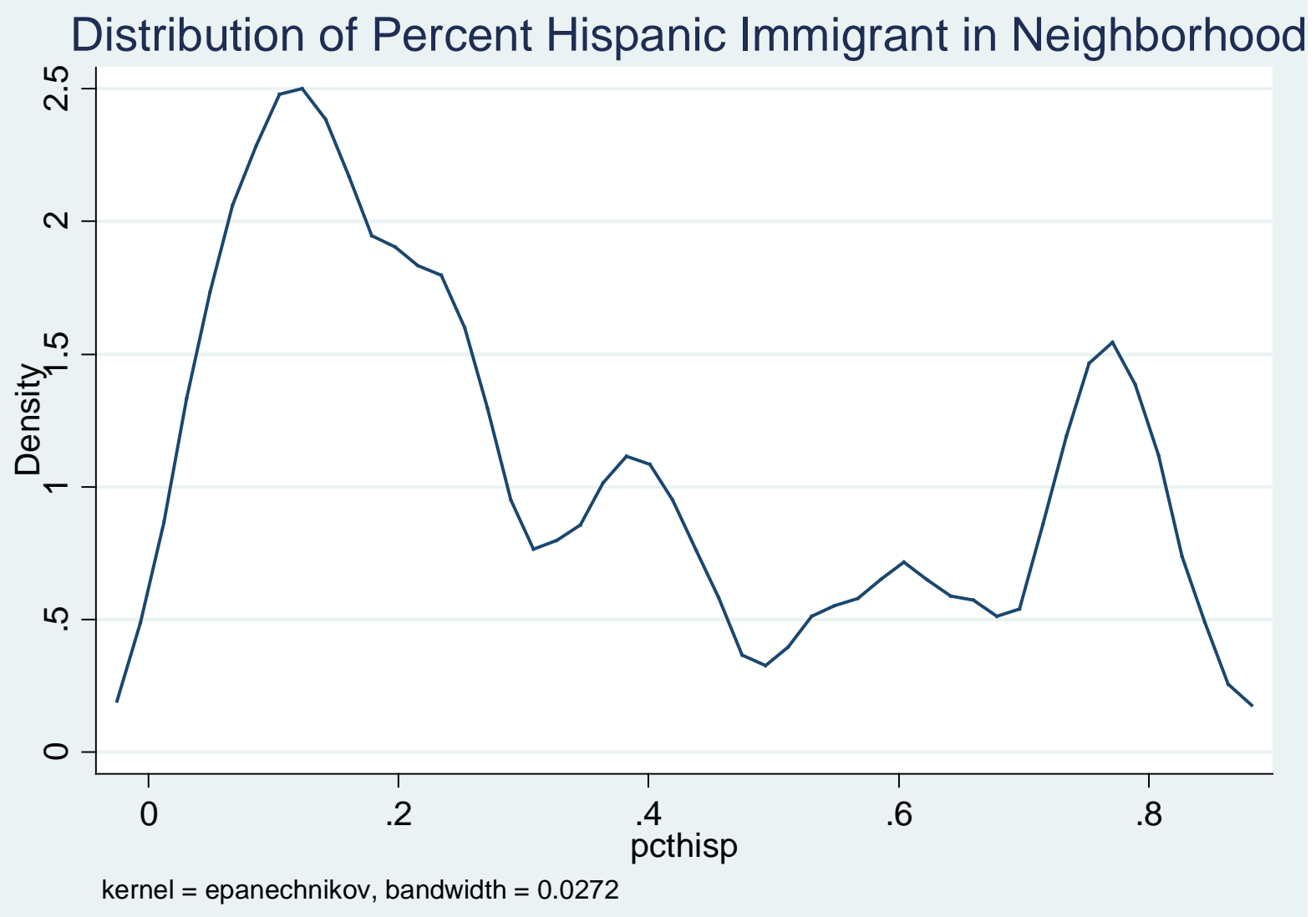


Figure 4: Distribution of percent own-origin immigrants in zip code of residence, Hispanic immigrants

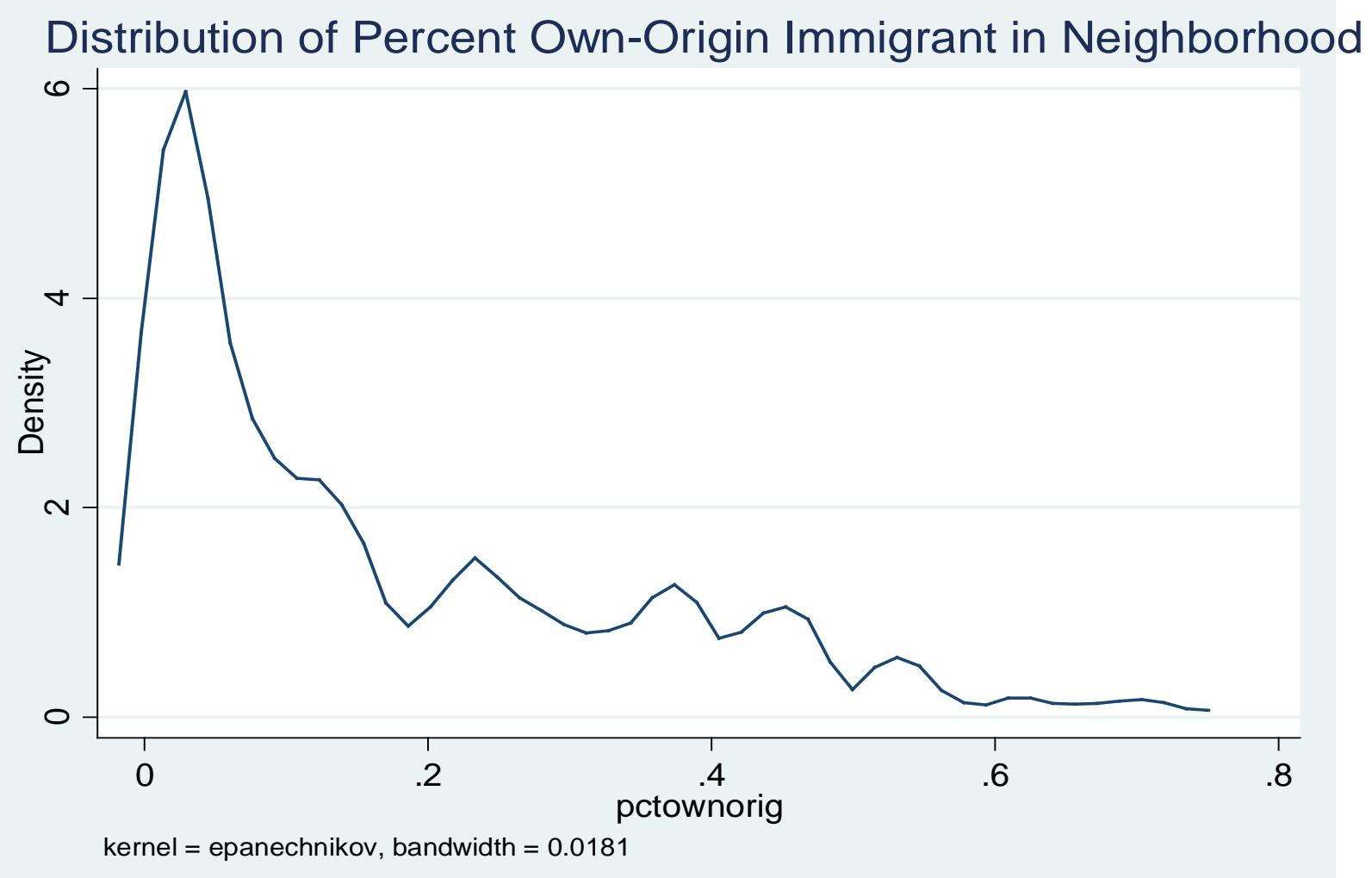


Figure 5: Time series of WIC participation rates, stratified by percent own origin in neighborhood

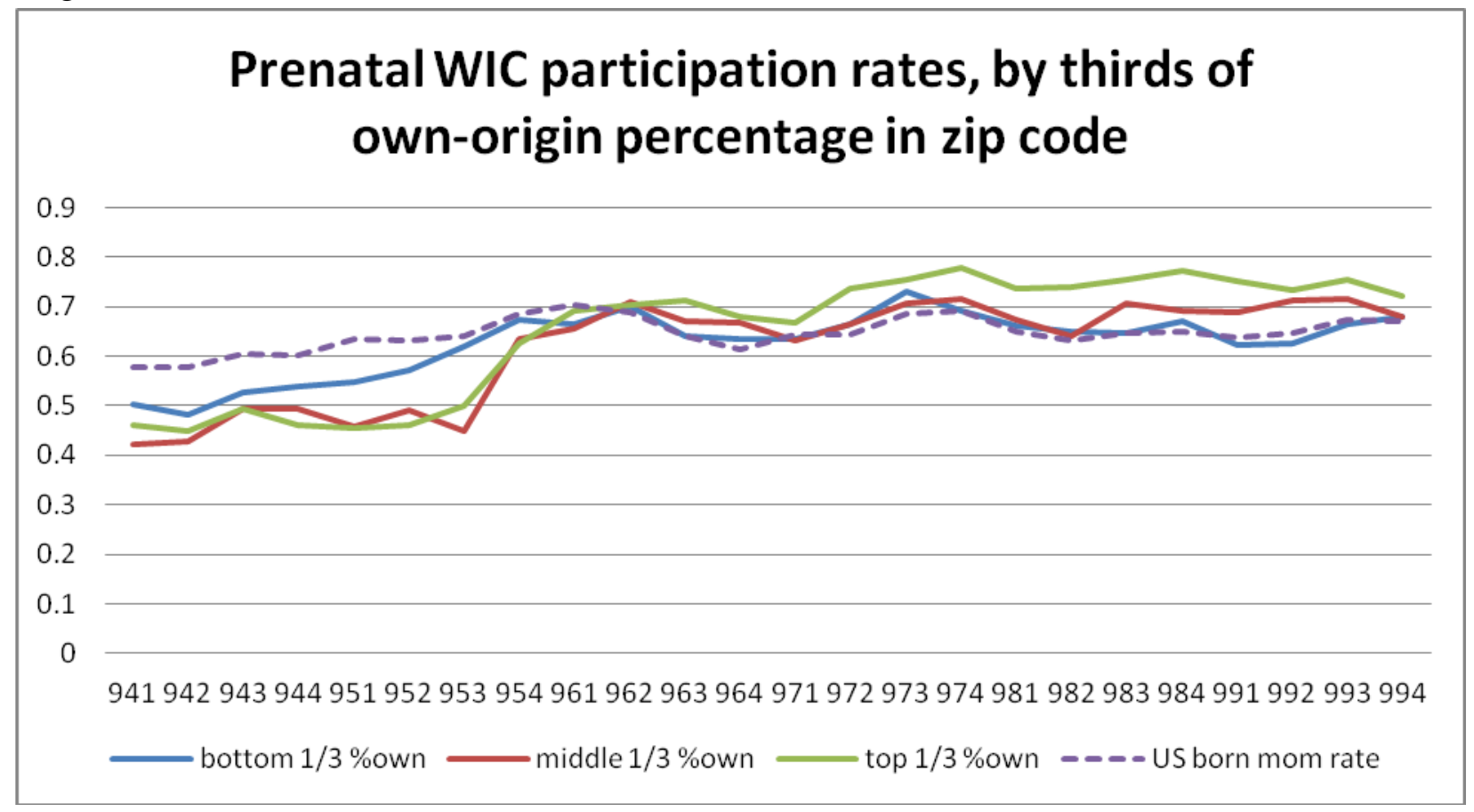


Figure 6: Time series of WIC participation rates, zeroing on the identifying variation used in the analysis

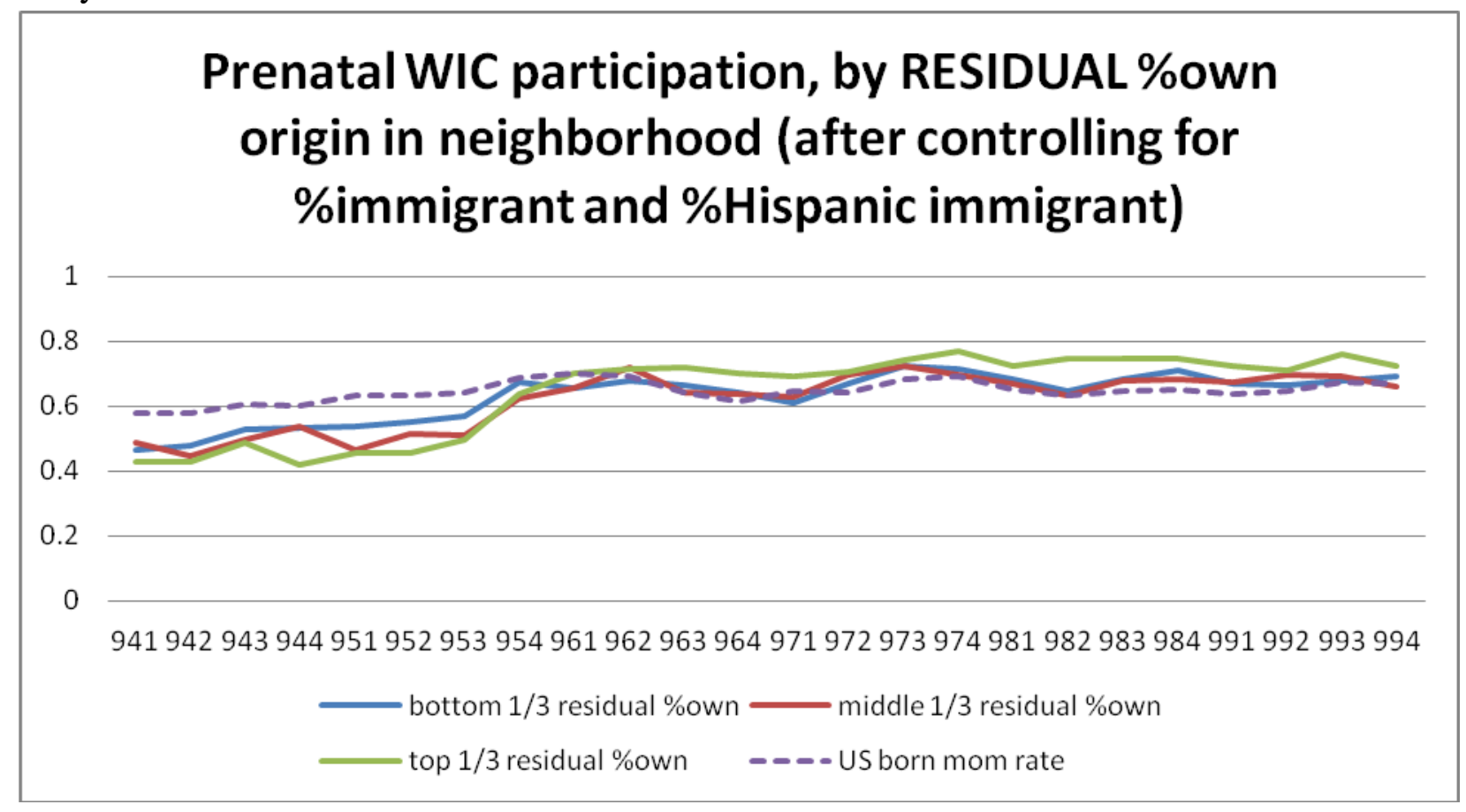


Figure 7: Quarterly estimates of the effects of percentage own origin on Hispanic immigrants' WIC participation rate, holding constant time-specific effects of percentage Hispanic immigrant and percentage immigrant in the neighborhood

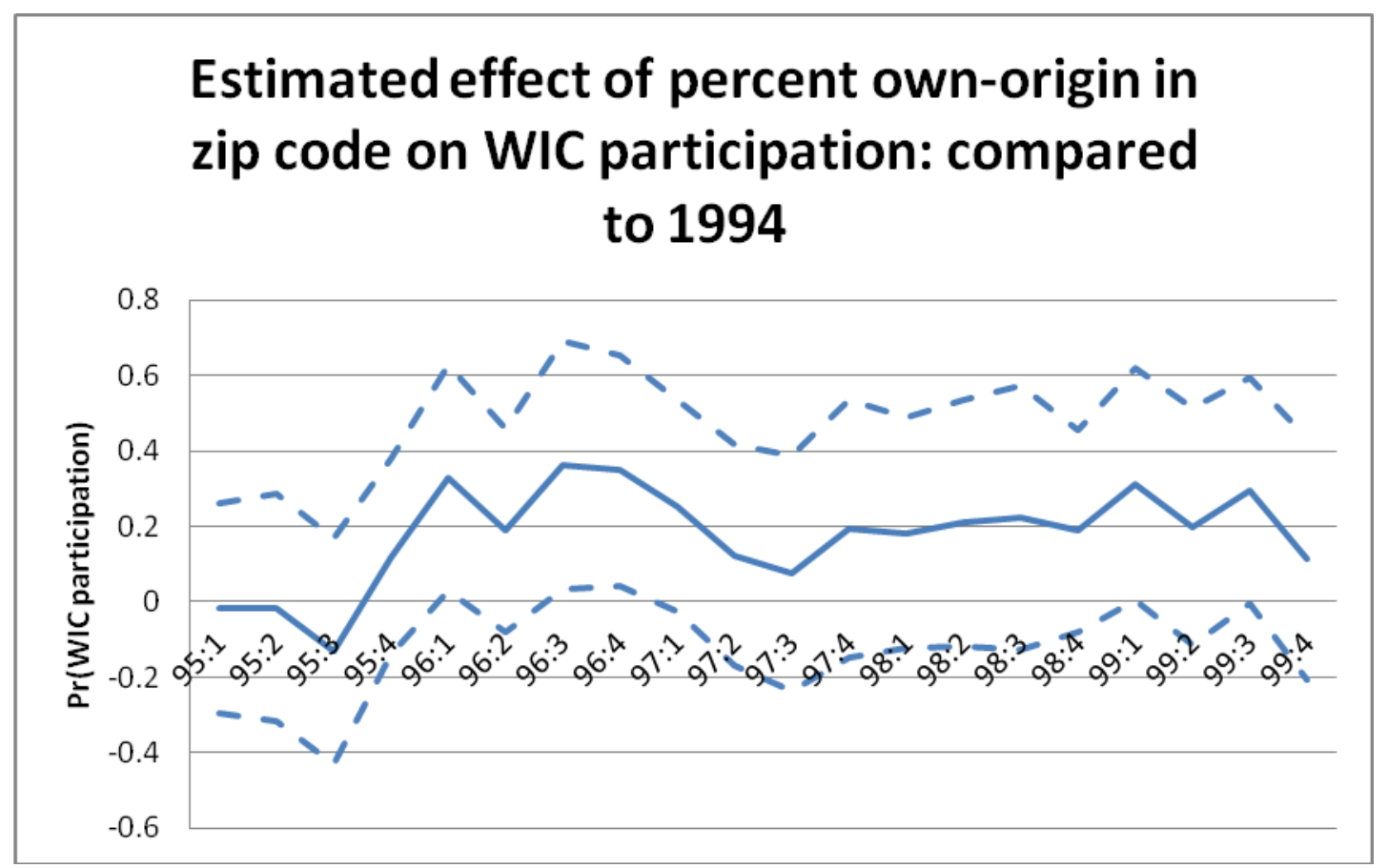

